\title{
Characteristics of the summer atmospheric boundary layer height over the Tibetan Plateau and influential factors
}

\author{
Junhui Che ${ }^{1,2,3}$ and Ping Zhao ${ }^{1,2}$ \\ ${ }^{1}$ State Key Laboratory of Severe Weather, Chinese Academy of Meteorological Sciences, Beijing, 100081, China \\ ${ }^{2}$ Collaborative Innovation Center on Forecast and Evaluation of Meteorological Disasters, \\ Nanjing University of Information Science and Technology, Nanjing, 210044, China \\ ${ }^{3}$ Shandong Meteorological Service Center, Jinan, 250031, China
}

Correspondence: Ping Zhao (zhaop@ cma.gov.cn)

Received: 29 July 2020 - Discussion started: 24 September 2020

Revised: 15 February 2021 - Accepted: 16 February 2021 - Published: 6 April 2021

\begin{abstract}
The important roles of the Tibetan Plateau (TP) atmospheric boundary layer (ABL) in climate, weather, and air quality have long been recognized, but little is known about the TP ABL climatological features and their west-east discrepancies due to the scarce data in the western TP. Based on observational datasets of intensive sounding, surface sensible heat flux, solar radiation, and soil moisture from the Third Tibetan Plateau Atmospheric Scientific Experiment (TIPEXIII) and the routine meteorological-operational-sounding and ground-based cloud cover datasets in the Tibetan Plateau for the period 2013-2015, we investigate the west-east differences in summer ABL features over the TP and the associated influential factors for the first time. It is found that the heights of both the convective boundary layer (CBL) and the neutral boundary layer (NBL) exhibit a diurnal variation and a west-east difference in the TP, while these features are not remarkable for the stable boundary layer (SBL). Moreover, the ABL shows significant discrepancies in the amplitude of the diurnal variation and the persistent time of the development between the eastern and western TP. In the early morning (08:00 BJT, Beijing time), the ABL height distribution is narrow, with a mean height below $450 \mathrm{~m}$ a.g.l. (above ground level) and a small west-east difference. The SBL observed at this moment accounts for $85 \%$ of the total TP ABL. There is a wide distribution in the ABL height up to $4000 \mathrm{~m}$ a.g.l. and a large west-east difference for the total ABL height at noon (14:00 BJT), with a mean height above $2000 \mathrm{~m}$ a.g.l. in the western TP and around $1500 \mathrm{~m}$ a.g.l. in the eastern TP. The CBL accounts for $77 \%$ of the total TP ABL at this moment, with more than $50 \%$ of the CBL above $1900 \mathrm{~m}$ a.g.l. In the
\end{abstract}

late afternoon (20:00 BJT), the CBL and SBL dominate the western and eastern TP, respectively, which results in a larger west-east difference of $1054.2 \mathrm{~m}$ between the western and eastern TP. The high ABL height in a cold environment over the western TP (relative to the plain areas) is similar to that in some extreme hot and arid areas such as Dunhuang and Taklimakan deserts. In general, for the western (eastern) TP, there is low (high) total cloud coverage, with large (small) solar radiation at the surface and dry (wet) soil. These features lead to high (low) sensible heat flux and thus promote (inhibit) the local ABL development. This study provides new insights for west-east structures of the summer ABL height, occurrence frequency, and diurnal amplitude over the TP region and the associated reasons.

\section{Introduction}

The atmospheric boundary layer (ABL) commonly refers to the bottom layer of the troposphere directly coupled with the earth's surface at a response timescale of about $1 \mathrm{~h}$ or less, in which a variety of complex motions characterized by turbulence may be present (Stull, 1988). The turbulent motions in the ABL are responsible for the atmospheric mixing processes, which affect the vertical redistribution of water vapour, momentum, heat, and atmospheric pollutants (Stull, 1988; Garratt, 1992; Huang et al., 2007; Miao et al., 2015). The ABL height (ABLH) as a fundamental variable is critical to diagnose turbulent mixing, vertical disturbance, convective transport, pollutant dispersion, and atmospheric environ- 
mental and effective heat capacity (Garratt, 1993; Seibert et al., 2000; Guo et al., 2009; Esau and Zilitinkevich, 2010; Dai et al., 2014; Pal and Haeffelin, 2015; Davy and Esau, 2016). Therefore, the accurate specification of the ABLH is essential to develop weather, climate, and air pollution prediction models.

The cloud-free ABL overland can be divided into three types, that is, the convective boundary layer (CBL), the stable boundary layer (SBL), and the neutral boundary layer (NBL) (Stull, 1988). The CBL usually has the strongest turbulence forced by surface buoyancy flux with or without wind shear and is generally capped by a strong temperature inversion maintained through large-scale subsidence. The CBL height is a result of the balance of the turbulence-induced entrainment and the subsidence velocity (e.g. Driedonks and Tennekes, 1984). However, turbulence in the SBL is mainly driven by the mean wind shear against negative buoyancy flux from the stable thermal stratification within the nocturnal surface inversion (NSI). The SBL height is hence related to the boundary layer wind and wind shear, which sometimes are used to identify the SBL height. The NBL occurs in neutral conditions, with a turbulence of almost the same intensity in all directions (Stull, 1988; Blay-Carreras et al., 2014). It denotes the type of boundary layer with solely wind forcing and normally occurs during the transition from the daytime CBL to the night-time SBL. It can also occur anytime when the buoyancy forcing is weak. The ABLH variability is dominated by its strong diurnal cycle (Stull, 1988; Garratt, 1992). In this diurnal cycle, the different manifestations of an ABLH are generated in response to the distinct forcing mechanisms that originate from mechanical (wind shear) and thermal (buoyancy) effects (Stull, 1988; Garratt, 1992). Over land and after sunrise, the surface is heated by solar radiation, resulting in upward heat flux that initiates strong updraughts of warm air. Such a mechanism generates a deepening of the CBL (Chen and Houze, 1997). At sunset, the surface cools more rapidly compared to the air above, resulting in negative heat flux that consumes turbulent kinetic energy. Consequently, shear-driven turbulence can only maintain a shallow SBL with the formation of the NSI (Y. Zhang et al., 2011; Miao et al., 2015). Above the NSI, the convective-energycontaining eddies start to lose their strength and mixing capacity. This deep and near-adiabatic vertical region, which is the remnant of the daytime CBL, is known as the residual layer (RL). The use of precise information on the RL in numerical models is of fundamental importance when describing the evolution of the diurnal CBL (Blay-Carreras et al., 2014; Chen et al., 2016).

The ABLH can be calculated from temperature, humidity, and wind profiles (Holtslag and Boville, 1993; Seibert et al., 2000; Seidel et al., 2010; Bosveld et al., 2014; Davy, 2018). The CBL height is generally less than $2000-3000 \mathrm{~m}$ a.g.l. (above ground level) and the SBL thickness is usually less than 400-500 m a.g.l. (Garratt, 1992). The ABL height shows an obvious spatial variation due to differences in topography, thermal properties of the underlying surface, and weather conditions. For example, the CBL can grow to a height of 4700 m a.g.l. in New Delhi before the outbreak of the South Asian monsoon, whereas it only reaches $900 \mathrm{~m}$ a.g.l. in Bangalore during the monsoon period (Raman et al., 1990). Seidel et al. $(2010,2012)$ pointed out that a large east-west spatial gradient of the ABLH at sunset in the United States spanning several time zones may be conflated with the diurnal variations in the $\mathrm{ABL}$ for the local solar time in the west earlier than in the east at fixed observation times. Guo et al. (2016) identified three large-scale ABLH spatial patterns in China, that is, a west-east gradient during sunrise, an east-west gradient during sunset, and a south-north gradient at noon. The reasons for the first two patterns are similar to those in the United States shown in Seidel et al. (2012), while the south-north gradient may be related to the local surface and hydrological processes (Guo et al., 2016; Zhang et al., 2017).

The Tibetan Plateau (TP), with an average elevation exceeding $4000 \mathrm{~m}$, is characterized by complex land surface processes and boundary layer structures (Tao and Ding, 1981; Yanai and Li, 1994; Xu et al., 2002; Yang et al., 2004; Li and Gao, 2007; Sun et al., 2007; Zhou et al., 2018; Zhao et al., 2019a). The ABLH in the TP can reach 2000$3000 \mathrm{~m}$ a.g.l., generally higher compared to some plain areas (with ABLH of 1000-1500 m a.g.1.) (Ye and Gao, 1979; Zhao and Miao, 1992; Xu et al., 2002; Zhang et al., 2003). The ABLH in the TP varies greatly with location and season. At Gaize station of the western TP, the super-thick ABLH may exceed $5000 \mathrm{~m}$ a.g.l. during winter (Chen et al., 2013, 2016). In the central TP, the ABLH is lower, between 400 and $1800 \mathrm{~m}$ a.g.l. at Dangxiong station and $1750 \mathrm{~m}$ a.g.l. at Namtso Lake (Li et al., 2000; Liu et al., 2001, and Lü et al., 2008). Moreover, there is also a significant difference in the TP ABLH between dry and rainy seasons (Zuo et al., 2004). For instance, the ABLH at Naqu station is $2211-4430 \mathrm{~m}$ a.g.l in the dry season, while it is 1006-2212 m a.g.l. in the rainy season (Li et al., 2011).

Although observations and studies for the TP ABL features have made progress, routine meteorologicaloperational-sounding observations are scarce in the western TP due to the local high elevations, naturally harsh environmental conditions, and logistic challenges. The previous studies on the ABL in the western TP are usually based on observational data at Shiquanhe (during $15 \mathrm{~d}$ in one summer) and Gaize (during $22 \mathrm{~d}$ in one summer) stations (Song et al., 1984; Chen et al., 2013). Thus, the statistical representation of their results is limited. Moreover, there are significant differences in surface properties and general climate between the eastern and western TP (Wang et al., 2016). Few studies examined the west-east differences in the ABL features due to the scarce data in the western TP. To obtain longer observational data in the western TP, the Third Tibetan Plateau Atmospheric Scientific Experiment (TIPEX-III) has made routine sounding launches at Shiquanhe, Gaize, and Shenzha 

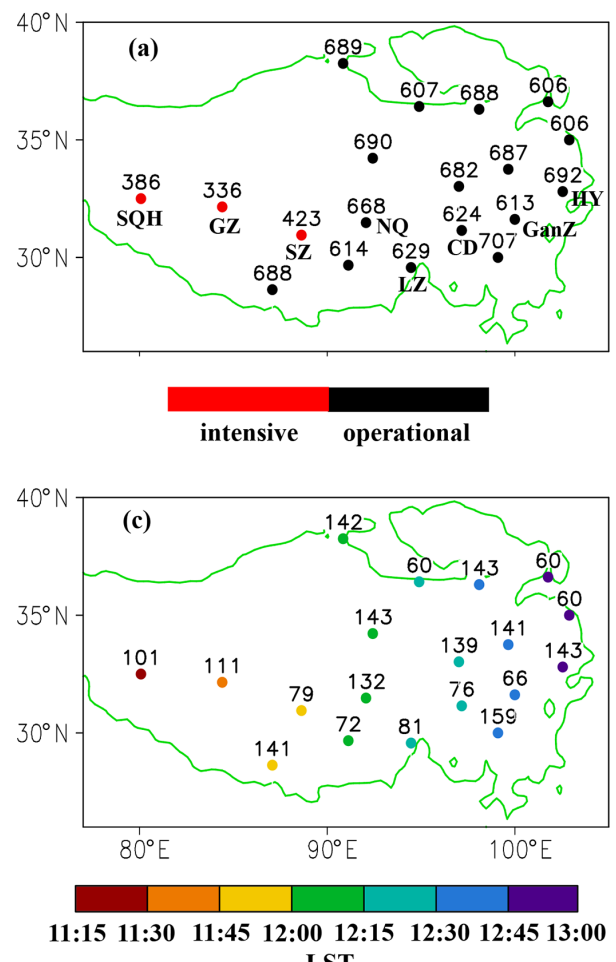

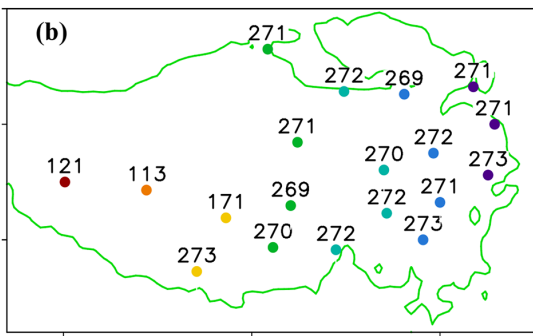

05:15 05:30 05:45 06:00 06:15 06:30 06:45 07:00 LST

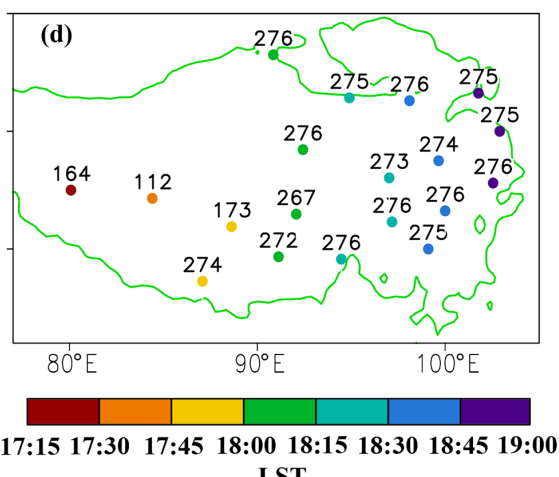

Figure 1. Distribution of sounding stations, in which the number indicates sounding profiles at each station at (a) 08:00, 14:00, and 20:00 BJT; (b) 08:00 BJT; (c) 14:00 BJT; and (d) 20:00 BJT in the study period. Red (black) dots represent intensive (operational) observations, and some observation station names are given as abbreviations in (a). Coloured dots represent the local time of the BJT time in (b), (c), and (d). The green line shows the $3000 \mathrm{~m}$ topography.

stations of the western TP (Fig. 1) since 2013, which fills in the data gaps in the operational-sounding network over the western TP (Zhao et al., 2018). Meanwhile, the TIPEX-III also carried out the intensive-sounding observations in the TP and adjacent stations at 14:00 Beijing time (06:00 UTC) in June, July, and August (Zhao et al., 2019b). Compared to the previous field experiments over the TP, the TIPEX-III has a wider and longer coverage of sounding observations over the western TP, providing valuable observational data for studying the ABL features in the western TP and the west-east differences in these features in the TP during summer.

This study utilizes the TIPEX-III observational sounding data to investigate the features of the ABLH in the TP and their differences between the western and eastern TP during summer and analyses the major factors affecting the ABLH in the TP. The remainder of this paper is organized as follows. Main features of data and methods are described in Sect. 2. In Sect. 3, the characteristics of the ABLH in the eastern and western TP and their regional differences are analysed in detail. In Sect. 4, the major factors affecting the ABLH in the $\mathrm{TP}$ and the west-east differences are examined. Discussions and conclusions are given in Sect. 5.

\section{Data and analysis methods}

\subsection{Observation data}

The TIPEX-III has carried out the routine meteorologicalintensive-sounding observations at Shiquanhe $(\mathrm{SQH})$, Gaize (GZ), and Shenzha (SZ) stations of the western TP (marked by red dots in Fig. 1) since the 2013 summer (Zhao et al., 2018), which have been applied in research on the vertical structure of the upper troposphere and lower stratosphere at Gaize station during the rainy season and the effects of assimilating the intensive-sounding data on downstream rainfall (Hong et al., 2016; Yu et al., 2018; Zhao et al., 2018, 2019b). These intensive-sounding data and the routine meteorological-operational-sounding data at 16 stations of the east-central TP from the China Meteorological Administration (marked by black dots in Fig. 1) are utilized in this study. The sounding observations at the above intensiveand operational-sounding stations were carried out at 08:00 Beijing time (BJT; 00:00 UTC), 14:00 BJT (06:00 UTC), and 20:00 BJT (12:00 UTC) each day during summer (June, July, and August), including vertical profiles of temperature, humidity, and wind direction and speed. After the quality control of the observational sounding data, we select data from three time periods for this study: 15 June to 31 July 2013, 15 
June to 31 August 2014, and 1 June to 31 August 2015. There are 11635 sounding profiles (Fig. 1a) from 19 stations over the TP region consisting of 4745,2049 , and 4841 profiles at 08:00 BJT (Fig. 1b), 14:00 BJT (Fig. 1c), and 20:00 BJT (Fig. 1d), respectively. It is evident that the observational sample size used in this study is much larger compared to the previous studies. Meanwhile, it is noted that there is a large difference in the sample size between the intensive and operational observation records at 08:00 and 20:00 BJT (Fig. 1b and d), which is called the original dataset for convenience. Consequently, we also select the test group dataset, which contains the same intensive observation records as the operational ones at these two times, to conduct sensitivity analysis (shown in Sect. 3.2), which shows that the difference in the sample size between the intensive and operational observation records does not change our conclusions.

To analyse the factors affecting the ABL in the TP, we use the TIPEX-III 30 min mean surface sensible heat flux (SHF), downward solar radiation, and $5 \mathrm{~cm}$ soil volume moisture content at $\mathrm{SQH}$ (bare soil with less vegetation), Naqu (NQ; alpine steppe), and Linzhi (LZ; alpine meadow with few shrubs and trees) stations in the 2014-2015 summers (Wang et al., 2016; Zhao et al., 2018; Li et al., 2019, 2020). In addition, the manual operational ground-based cloud cover observations at 02:00, 08:00, 14:00, and 20:00 BJT from the China Meteorological Administration are also used in this study. These ground-based cloud cover data have been utilized by Guo et al. (2016) and Zhang et al. (2017).

\subsection{Calculation method of ABLH}

The potential-temperature-gradient method, proposed by Liu and Liang (2010) and sketched in Fig. 2a, is utilized in identifying the ABL type and calculating the ABL height. The CBL height is defined at the base of the overlying inversion layer that caps the rising convective thermals. The SBL height is defined as the top of the underlying inversion layer, where turbulence decreasing from the surface nearly ceases (Stull, 1988). In the evening and morning transition periods when the RL may occur, the neutral RL starting from the surface is identified with near-neutral conditions in the surface layer (that is the NBL). Following Liu and Liang (2010), Zhang et al. (2017), and Zhao et al. (2019), the original sounding observation profiles with a fine vertical resolution of $\sim 1 \mathrm{hPa}$ are interpolated to a vertical resolution of $5 \mathrm{hPa}$ (corresponding to a vertical interval around $50 \mathrm{~m}$ in the ABL) by the nearest-neighbour interpolation method. On the basis of the near-surface thermal gradient, such as a potential-temperature $(\theta)$ difference (PTD) between the fifth layer $\left(\sim 250 \mathrm{~m} ; \theta_{5}\right)$ and the second layer $\left(\sim 50 \mathrm{~m} ; \theta_{2}\right)$, the $\mathrm{ABL}$ is classified as follows:

$$
\mathrm{PTD}=\theta_{5}-\theta_{2} \begin{cases}<-\sigma, & \text { for CBL } \\ >+\sigma, & \text { for SBL } \\ \geq-\sigma \text { and } \leq+\sigma, & \text { for NBL }\end{cases}
$$

Here $\sigma$ is the stability threshold of the near-surface potential-temperature stratification. Since the neutral stratification condition $(\sigma=0)$ is rare in nature, consistent with Liu and Liang (2010), $\sigma$ is set to $1.0 \mathrm{~K}$. The threshold value of the NBL is set to -1.0 to 1.0. Consequently, SBLs and CBLs with weakly stable or weakly unstable stratification are possibly identified as NBLs.

Once the boundary layer regime has been identified, we use the criteria defined by Liu and Liang (2010) to estimate the ABLH for each regime. Since buoyancy is the dominant mechanism driving turbulence in the CBL, the ABLH is defined as the height at which an air parcel rising adiabatically from the surface becomes neutrally buoyant (Stull 1988). First, we find the lowest level ( $\left.k_{1}\right)$ (Fig. 2a) that meets the following condition:

$\theta_{k_{1}}-\theta_{1} \geq \sigma_{u}$,

in which $\sigma_{u}$ is the $\theta$ increment that represents the minimum strength of the unstable layer. Once level $k_{1}$ is determined, another upward scan is performed to find the lowest level at which the potential-temperature gradient with height $\left(\dot{\theta}_{k}\right)$ meets the following criterion:

$\dot{\theta}_{k} \equiv \frac{\partial \theta_{k}}{\partial z} \geq \dot{\theta}_{r}$.

Here $\dot{\theta}_{r}$ is the minimum strength for the overlying inversion layer and can be considered to be the overshooting threshold of the rising parcel to define the scope of the entrainment zone for the CBL. The same procedure is adopted to determine the NBL height excluding the entrainment zone at the top (Fig. 2a). Various values of $\sigma_{u}$ and $\dot{\theta}_{r}$ will affect the determination of the boundary layer height, and they are respectively set to $0.5 \mathrm{~K}$ and $4.0 \mathrm{~K} \mathrm{~km}^{-1}$, consistent with Liu and Liang (2010). Quantifying the uncertainty in the rawinsondebased approach, which is closely related to the thermodynamic characteristics of the sounding profiles for identifying ABLH, is important (Seidel et al., 2010, 2012; Davy, 2018; Lee and Pal, 2021). The ABLH determined by this potentialtemperature-gradient method from soundings is highly consistent with that derived from lidar measurements, with a correlation coefficient of 0.96 and root mean square error of $211 \mathrm{~m}$ (Liu and Liang 2010). Moreover, the changes in ABLHs are $\leq 177 \mathrm{~m}$ when using $3.5,4$, and $4.5 \mathrm{~K} \mathrm{~km}^{-1}$ as $\dot{\theta}_{r}$, respectively (Zhang et al., 2017). It is evident that the uncertainties in the above procedure can be negligible for both CBL and NBL since most of their ABLHs are much higher. For the SBL, the turbulence in the ABL can result from either buoyancy forcing or wind shear. The SBL height is defined as the lower of the heights of both the thermal stable layer from the surface and the maximum wind in the lowlevel jet stream if present. More details of the definitions of the boundary layer regimes may be seen in Liu and Liang (2010). Figure $2 \mathrm{c}$ and d show the typical profiles of potential temperature for CBL, NBL, and SBL at 20:00 BJT on 10 




Figure 2. (a) Illustration of the determination procedure for the convective boundary layer (CBL), neutral boundary layer (NBL), and stable boundary layer (SBL) heights and examples of the potential-temperature (PT) profiles derived from sounding observation at Lasa station at 20:00 BJT for (b) CBL on 10 June 2013, (c) NBL on 21 July 2013, and (d) SBL on 11 August 2013, respectively. The dashed line in (b-d) represents the ABL height identified using the algorithm described.

June 2013, 21 July 2013, and 11 August 2013 at Lasa station, and the ABL heights calculated by the potential-temperaturegradient method are 3465, 1258, and 409 m a.g.l., respectively.

\section{Characteristics of the summer ABLH in the eastern and western TP}

\subsection{A general characteristic of the ABLH}

The diurnal variation is an important feature of the $\mathrm{ABL}$, consisting of different periods of daytime, night-time, and day-night transitions (Liu and Liang, 2010). In the central TP (near $90^{\circ} \mathrm{E}$ ), 08:00, 14:00, and 20:00 BJT correspond to 06:00 (the early morning), 12:00 (noon), and 18:00 (the late afternoon) local solar time (LST) (Fig. 1b and c), respectively. To reveal a difference in ABLH between the eastern TP (ETP) and the western TP (WTP), we divide all sounding stations in the TP into two groups. One is for the WTP (to the west of $92.5^{\circ} \mathrm{E}$ ), with 8 stations, and the other is for the ETP (to the east of this longitude), with 11 stations.
Figure $3 a-c$ show the spatial distributions of the mean ABLH over the TP at 08:00, 14:00, and 20:00 BJT, respectively. In the early morning (08:00 BJT), the ABL is of the night-time property. The ABLH is generally low (< $450 \mathrm{~m}$ a.g.l.) over the TP and displays a relatively homogeneous feature (Fig. 3a). At this moment, the distribution of the ABLH is narrow, with a frequency peak of $35 \%$ at an ABLH of 300 ma.g.l. (Fig. 3d) and $78.5 \%$ (99.6\%) of the ABLH below 500 (1000) m a.g.l. (Fig. 3e). Figure $3 f$ displays the zonal sections of the ABLH along $32^{\circ} \mathrm{N}$, in which the cross-section includes SQH, GZ, SZ, NQ, Changdu (CD), Ganzi (GanZ), and Hongyuan (HY) stations. In this figure, the ABLH varies between 218.4 and $433.9 \mathrm{~m}$ a.g.l. from east to west and presents a relatively homogeneous feature in the west-east direction.

At noon (14:00 BJT), with the well-developed daytime ABL (Fig. 3b), its height remarkably increases over the TP, with an average of $1887.7 \mathrm{~m}$ a.g.l., and exhibits a large west-east difference. There is a wide distribution of the ABLH up to $4000 \mathrm{~m}$ a.g.l., with a relatively flat peak between 900 and 2900 ma.g.l. (Fig. 3d) and only $17.8 \%$ (more than $50 \%$ ) of the ABLH below $1000 \mathrm{~m}$ a.g.l. (above 1900 m a.g.l.) (Fig. 3e). At this moment, the regional mean 



Figure 3. Spatial distribution of the mean ABL height (ABLH) at (a) 08:00 BJT, (b) 14:00 BJT, and (c) 20:00 BJT; (d) the regional mean frequency and (e) cumulative frequency distributions of the ABLH in the TP at 08:00, 14:00, and 20:00 BJT; (f) the west-east cross-sections of the ABLH along $32^{\circ} \mathrm{N}$ (indicated by red line in c) at 08:00, 14:00, and 20:00 BJT.

ABLH is $2124.2 \mathrm{~m}$ a.g.l. in the WTP and $1693.5 \mathrm{~m}$ a.g.l. in the ETP, with a mean difference of $430.7 \mathrm{~m}$ between the WTP and the ETP. Along $32^{\circ} \mathrm{N}$, the ABLH remarkably increases from $1379.4 \mathrm{~m}$ a.g.l. at GanZ station to $2504.2 \mathrm{~m}$ a.g.l. at SQH station, with the west-east difference exceeding $1200 \mathrm{~m}$ (Fig. 3f). This regional difference in the TP ABLH could be likely related to the hydrologic factors such as air moisture and soil water (also see Sect. 4) that may modulate the spatial distribution of the daytime ABLH (Seidel et al., 2012).

In the late afternoon (20:00 BJT), the ABL begins to show the night-time features. The ABLH also starts to decrease in the ETP, with the regional mean height $<1000 \mathrm{~m}$ a.g.l., while it continues to increase at the westernmost stations, with the regional mean height $>2000 \mathrm{~m}$ a.g.l. (Fig. 3c). This result indicates a larger west-east difference $(1054.2 \mathrm{~m})$ between the WTP and the ETP. Especially, the ABLH is $602 \mathrm{~m}$ a.g.l. at $\mathrm{HY}$ station and $2920.6 \mathrm{~m}$ a.g.l. at SQH station, with a difference above $2000 \mathrm{~m}$ between these two stations (Fig. 3f). At this moment, the frequency of the high ABLH decreases, with $12.8 \%$ of the frequency peak at an ABLH of 300 m a.g.l. (Fig. 3d) and $50 \%$ of the ABL heights less than $1000 \mathrm{~m}$ a.g.l. (Fig. 3e). It is evident that the west-east difference in the ABLH over the TP increases from noon to the late afternoon (LST). During the evening transition, the daytime boundary layer undergoes a transition to the night-time boundary layer. Since the TP spans almost 1.5 time zones from west to east (Fig. 1c), the local solar time is earlier in the west (where 20:00 BJT corresponds to 17:20 LST in the westernmost $\mathrm{SQH}$ station) compared to the east (where 20:00 BJT corresponds to 18:50 LST for the easternmost HY station), which supports an earlier transition from the daytime $\mathrm{ABL}$ to the night-time $\mathrm{ABL}$ in the east (Seidel et al., 2010, 2012; Guo et al., 2016; Lee and Pal, 2017). Meanwhile, it is noted that this difference in the local time is less over the TP than over China (Guo et al., 2016) and the United States (Seidel et al., 2010, 2012; Lee and Pal, 2017). Thus the contribution of the time zone difference to the regional difference in ABLH is relatively smaller in the TP.

Figure 4 further shows the variations in the ABLH from 08:00 to 14:00 BJT and from 14:00 to 20:00 BJT, indicating varying rates in $6 \mathrm{~h}$. It is seen from Fig. $4 \mathrm{a}$ that the ABLH in the TP increases substantially from 08:00 to 14:00 BJT, with a mean growth rate of $1500 \mathrm{~m} / 6 \mathrm{~h}$. There is also a large westeast difference in the ABLH growth rate in this period, with a regional mean of $1800 \mathrm{~m} / 6 \mathrm{~h}$ and $1300 \mathrm{~m} / 6 \mathrm{~h}$ in the WTP and the ETP, respectively. From 14:00 to 20:00 BJT (Fig. 4b), the growth rate of the ABLH is negative in the ETP, exhibiting an opposite trend to that in Fig. 4a, which indicates a significant decrease (around $-600 \mathrm{~m} / 6 \mathrm{~h}$ ) in the ABLH after noon. In the WTP, the growth rate generally shows a weak increase (around $400 \mathrm{~m} / 6 \mathrm{~h}$ ) or decrease (around $-140 \mathrm{~m} / 6 \mathrm{~h}$ ). It is evident that the growth rate from 08:00 to 14:00 BJT may indicate the amplitude of the ABL diurnal variation over the TP. Compared to the ETP, the ABL in the WTP has the larger amplitude of the diurnal variation and the longer development time.

\subsection{Characteristics of SBL, NBL, and CBL heights}

We further examine the characteristics of different $\mathrm{ABL}$ types. Figure 5 presents the spatial distribution of occurrence frequency of SBL, NBL, and CBL at 08:00, 14:00, and 20:00 BJT. It is seen that the occurrence frequency exhibits significant discrepancies at different times for the SBL and CBL. At 08:00 BJT, the occurrence frequency of the SBL (CBL) is large (little) (Fig. 5a and Fig. 5g, respectively), 




Figure 4. Spatial distribution of the ABLH growth rate from 08:00 to 14:00 BJT (a) and from 14:00 to 20:00 BJT (b).

with a mean value $84.9 \%(8.5 \%)$ over the TP. At 14:00 BJT, the occurrence of the SBL (CBL) remarkably decreases (increases), accounting for $3.1 \%$ (76.9\%) of the ABL (Fig. 5b and Fig. 5h, respectively). At 20:00 BJT, the SBL (CBL) mainly occurs in the ETP (WTP) (Fig. 5c and Fig. 5i, respectively), with a regional mean of $35.0 \%(65.0 \%)$. However, the NBL shows a relatively weaker temporal variation over the TP (Fig. 5d-f), with a mean occurrence frequency of $6.4 \%, 20.0 \%$, and $25.5 \%$ at 08:00, 14:00, and 20:00 BJT, respectively. The above results are consistent with the diurnal development of the ABL structure, including the SBL in the early morning, the CBL at noon, and different types of ABLs between the eastern and western TP in the late afternoon (LST) because of the latitudinal difference and the resultant difference in local solar times. Note that the observations were made simultaneously for all stations. Nevertheless, the daytime SBL and the night-time CBL may also occur with low frequencies in the TP, which is likely due to the "abnormal" forcing associated with certain synoptic conditions or cloud coverage (Medeiros et al., 2005; Poulos et al., 2002; Stull, 1988).

To analyse the temporal variations in the ABLH over the $\mathrm{TP}$, the ABL height-occurrence frequency relationships for the SBL, NBL, and CBL at 08:00, 14:00, and 20:00 BJT are presented in Fig. 6a-f. For the SBL, the frequency distribution of the ABLH shows a similar feature at three measurement times (Fig. 6a-c) and is characterized by a narrow single mode, with frequency peaks of $39.0 \%, 28.1 \%$, and $36.6 \%$ at an ABLH of 200, 300, and $300 \mathrm{~m}$ a.g.l. at 08:00, 14:00, and 20:00 BJT, respectively, which indicates small temporal variations in the SBL height because the SBL is inhibited. Moreover, the SBL height above $80 \%$ is $<600 \mathrm{~m}$ a.g.l, and the cumulative frequency of the SBL height exceeding $1000 \mathrm{~m}$ a.g.l. is low (near 0 ) at 08:00, 14:00, and 20:00 BJT (Fig. 6d-f). For the NBL and CBL, however, their heights vary strongly with time under the influence of surface heating in the daytime. At 08:00 BJT (Fig. 6a), the distributions of the NBL and CBL heights are narrow, with frequency peaks of $27.5 \%$ and $35.1 \%$ at an ABLH of $300 \mathrm{~m}$ a.g.l. for NBL and CBL, respectively, similar to that of the SBL, which is possibly due to the initial development of the CBL and NBL in the early morning (LST). At 14:00 BJT, the CBL and NBL have a wide distribution of the ABLH up to $4000 \mathrm{~m}$ a.g.l, with a relatively flat peak between 1000 and $3000 \mathrm{~m}$ a.g.l., which is remarkably different from a single peak of the SBL. The frequency of the NBL height between 500 and $3000 \mathrm{~m}$ a.g.l. is generally less than $5 \%$ (Fig. 6b), with a frequency peak of $6.1 \%$ at $1000 \mathrm{~m}$ a.g.l., and more than $50 \%$ of the NBL height exceeds $1700 \mathrm{~m}$ a.g.l. (Fig. 6e). The height of the CBL is higher, with a frequency peak near $4.5 \%$ between 1500 and $2500 \mathrm{~m}$ a.g.l. (Fig. 6b), and more than $50 \%$ of the CBL height is above $2000 \mathrm{~m}$ a.g.l. (Fig. 6e). These results show that the ABL develops well at noon (LST). When the ABL begins turning to the nigh-time property at 20:00 BJT (Fig. 6c and f), the distributions of the CBL and NBL heights are still wide, but the frequency of the high $\mathrm{ABL}$ height decreases, with a frequency peak below $500 \mathrm{~m}$ a.g.l. It is obvious that the CBL and NBL heights show similar results consistent with those from Zhang et al. (2017). Stull (1988) and Blay-Carreras et al. (2014) revealed that the NBL often occurs in the transition periods between the CBL and the SBL. Since these transitions occur rapidly, the NBL may have the same characteristics in the state variables as the CBL prior to the transition, although the dynamic forcing in the NBL may be weaker compared to the CBL.

To reveal the spatial variations in the ABLH over the TP, the distributions of mean SBL, NBL, and CBL heights at 08:00, 14:00, and 20:00 BJT are illustrated in Fig. 7. The SBL height is generally low and varies between 200 and $730 \mathrm{ma}$ a.l. at these times, with a mean height of $336.0 \mathrm{~m}$ a.g.l. at 08:00 BJT, $356.0 \mathrm{~m}$ a.g.l. at 14:00 BJT, and $321.9 \mathrm{~m}$ a.g.1. at 20:00 BJT (Fig. $7 \mathrm{a}-\mathrm{c}$ ), which indicates the weak spatial differences in the SBL height over the TP at three observation times. For the NBL and CBL, their heights are still low in the early morning (LST) (Fig. 7d and g), with the ABLH $<450 \mathrm{~m}$ a.g.l., and have small spatial differences. At noon (LST) (Fig. 7e and h), the NBL and CBL heights rapidly increase, especially in the WTP, which leads to a remarkable east-west gradient in the ABL height. At this moment, there is a regional mean NBL (CBL) height of $2074.6 \mathrm{~m}$ a.g.l. (2191.4 ma.g.l.) in the WTP and $1594.8 \mathrm{~m}$ a.g.1. (1788.0 $\mathrm{m}$ a.g.l.) in the ETP, with a difference of $479.8 \mathrm{~m}(403.4 \mathrm{~m})$ between the WTP and the ETP. In the late afternoon (LST) (Fig. 7f and i), the NBL (CBL) height continues to increase in the WTP, with a regional mean of $2092.0 \mathrm{~m}$ a.g.1. (2192.2 ma.g.1.), while the NBL (CBL) height begins to decrease in the ETP, with a regional mean of $1423.1 \mathrm{~m}$ a.g.l. (1237.2 $\mathrm{m}$ a.g.l.). This varying feature in the ETP and WTP results in larger differences of $668.9 \mathrm{~m}$ $(955.0 \mathrm{~m})$ in the NBL (CBL) height between the WTP and ETP. Thus there is a significant difference in the frequency distribution of the ABL height between the ETP and the WTP in the daytime (Fig. 6g). The cumulative frequency contours gradually go upward from east to west (Fig. 6h). The eastern TP is dominated by a low CBL height, with a peak of $14.4 \%$ at a height of $350 \mathrm{~m}$ a.g.l. (Fig. $6 \mathrm{~g}$ ) and $50 \%(5 \%)$ of the CBL height below $1000 \mathrm{~m}$ a.g.l. (above $2500 \mathrm{~m}$ a.g.l.) (Fig. 6h). For the WTP, the strong peak of $4 \%-10 \%$ cor- 


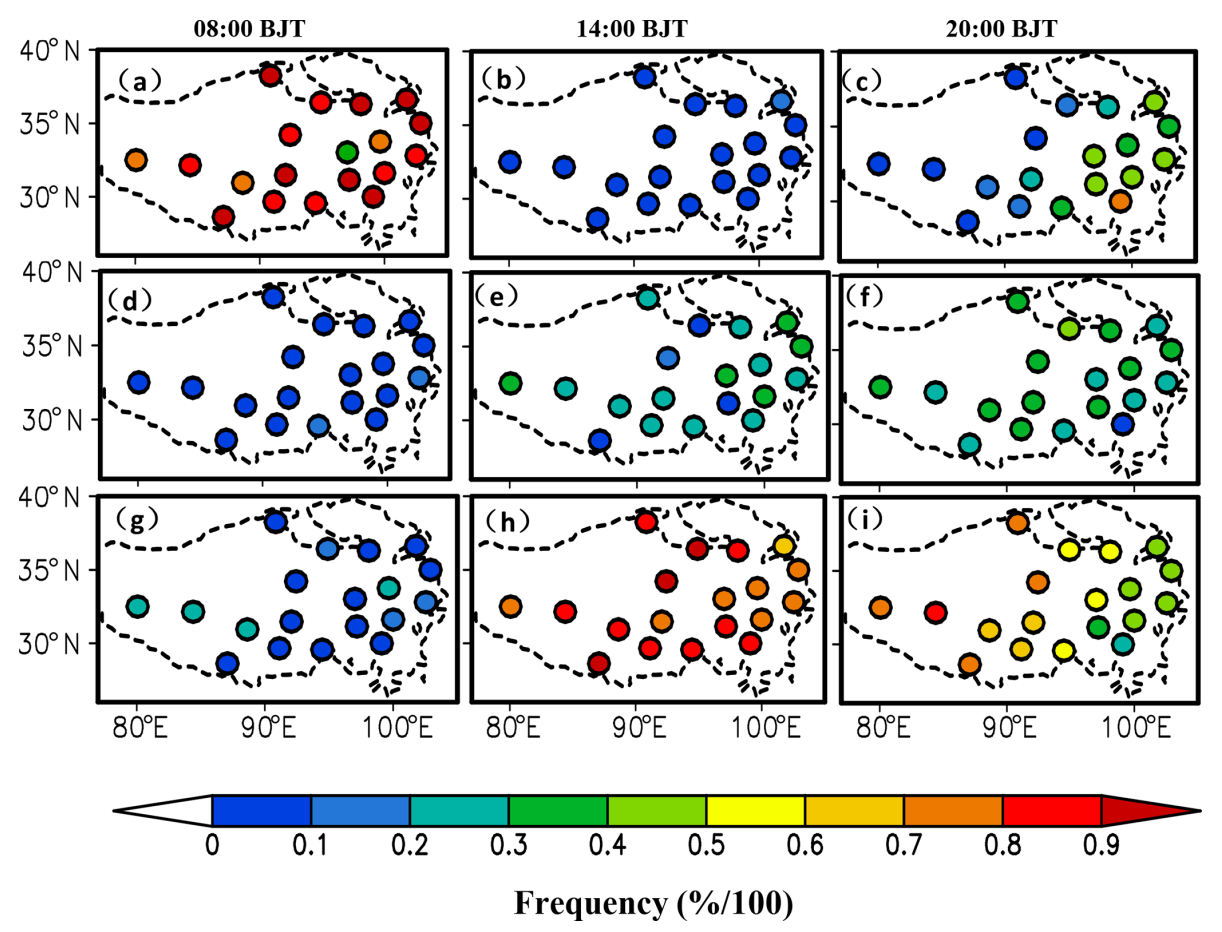

Figure 5. Spatial distribution of the occurrence frequency for the SBL (a-c), NBL (d-f), and CBL (g-i) at 08:00, 14:00, and 20:00 BJT.

responds to the high CBL between 2500 and $3500 \mathrm{~m}$ a.g.l. (Fig. 6g), especially at SQH station, and there are larger CBL heights, with almost $50 \%$ of the CBL extending upward to more than $2500 \mathrm{~m}$ a.g.l., almost $10 \%$ reaching $4000 \mathrm{~m}$ a.g.l. or higher, and only $15 \%$ of the CBL below 1000 ma.g.l (Fig. 6h).

To investigate an effect of differences in the sample profiles shown in Fig. 1b and d, we use the test group dataset to repeat the above analyses. Figures $8 \mathrm{a}$ and $\mathrm{b}$ show the scatter plots of the occurrence frequency of the SBL, NBL, and CBL from the original and test group datasets at each of the 19 stations at 08:00 and 20:00 BJT, respectively. It is seen that the correlation coefficients between the two datasets are 0.92-0.99, with root mean square errors (RMSEs) of the occurrence frequency between $1.1 \%$ and $2.7 \%$. Similar results are also seen in the SBL, NBL, and CBL heights at 08:00 BJT (Fig. 8c) and 20:00 BJT (Fig. 8d). The correlation coefficients in the ABL height are 0.90-0.99. The RMSE of the SBL height is $14 \mathrm{~m}$ and $25 \mathrm{~m}$ at 08:00 and 20:00 BJT, respectively. The RMSE of the CBL and NBL heights are 54-59 m at 08:00 BJT and 99-107 $\mathrm{m}$ at 20:00 BJT. These high correlations and small errors show that the difference in the sample size does not change our conclusions.

From the foregoing analysis, the CBL and NBL heights in the TP show remarkable temporal variations and west-east spatial differences, while these features are not remarkable for the SBL. From noon to the late afternoon (LST), the NBL and CBL are deeper in the WTP compared to the ETP, with the ABLH difference between the WTP and the ETP exceed- ing $600 \mathrm{~m}$ a.g.l. at 20:00 BJT. Then, which factors contribute to this difference in the ABL between the WTP and ETP? In the following section, we examine some factors that may be responsible for the ABL height over the TP.

\section{Factors responsible for the ABL height over the TP}

Previous studies have addressed effects of surface sensible heat flux (SHF), soil volume moisture content (VWC), downward-solar-radiation flux (DSR), and the cloud cover (CLD) on ABL height (Liu, et al., 2004; Zhao et al., 2011; Sanchez-Mejia and Papuga, 2014; Rihani et al., 2015; Lin et al., 2016; Zhang et al., 2017, 2019; Qiao et al., 2019). However, these studies paid little attention to reasons for the westeast difference in the ABL between the eastern and western TP. To investigate a possible reason for this difference, we utilize the TIPEX-III SHF, DSR, and VWC at SQH, NQ, and LZ stations and the corresponding meteorological operational CLD observations to analyse the relationships between these variables and the $\mathrm{ABL}$ height.

The driving force of turbulence in the ABL is the surface buoyancy flux as a result of surface and air temperature and humidity differences and the mean surface layer wind. The kinematic heat flux (KHF) and kinematic moisture flux (KMF) at the surface are the two factors directly responsible for the surface buoyancy flux (Brooks and Rogers, 2000). Since KMF is often small, KHF associated with SHF is examined as a major component of buoyancy flux in dry conditions over land. According to the method of Brooks and 

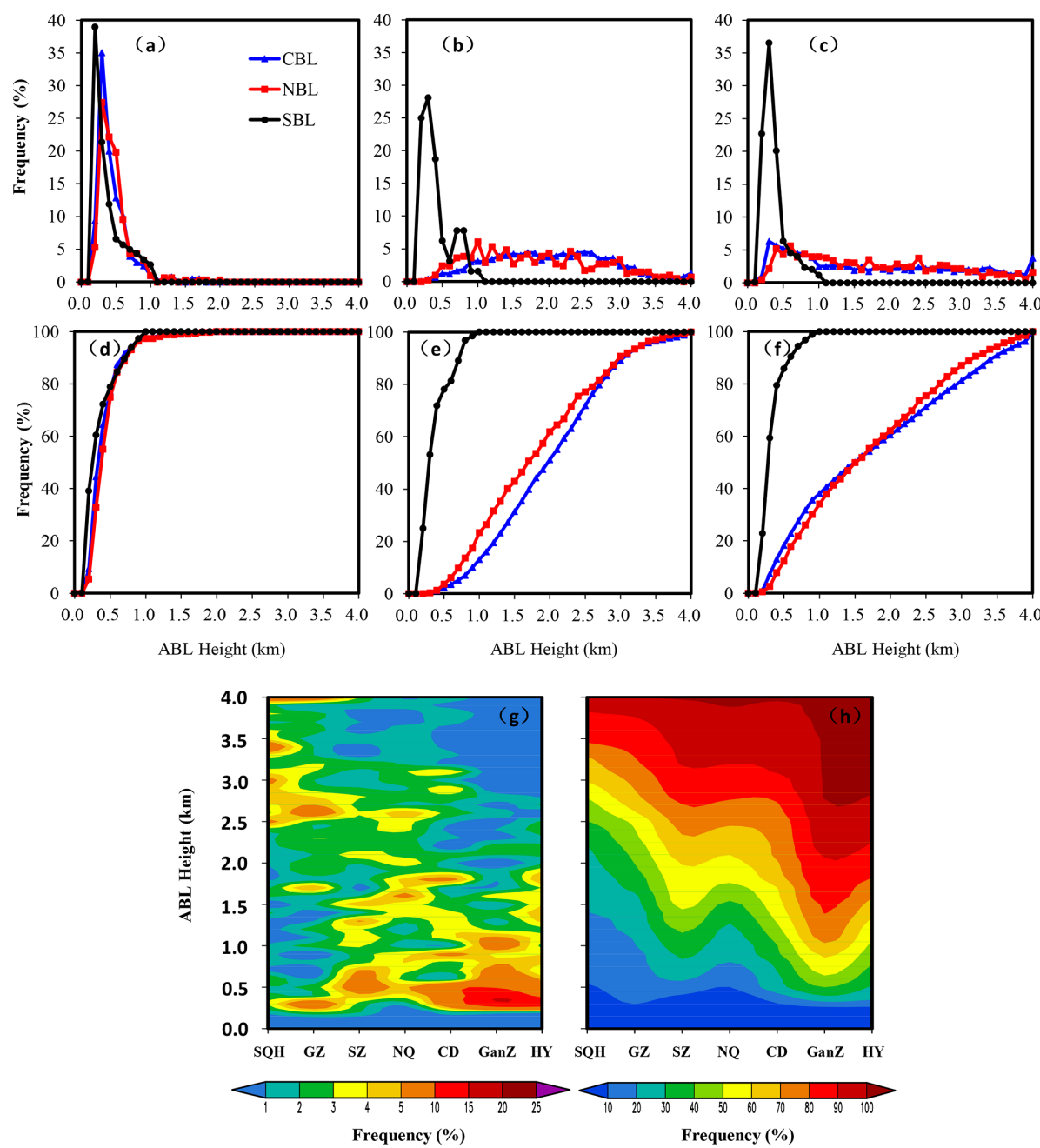

Figure 6. The regional mean frequency distributions of the ABLH over the TP for the CBL (blue), NBL (red), and SBL (black) at (a) 08:00 BJT, (b) 14:00 BJT, and (c) 20:00 BJT; (d-f) same as in (a-c) but for the cumulative frequency distributions; the west-east crosssections of frequency (g) and cumulative frequency (f) distributions of the CBL height along 32 $\mathrm{N}$ in the daytime (14:00 and 20:00 BJT).

Rogers (2000), our calculation results show that the contribution from KMF to surface buoyancy flux is below $18 \%$ at $\mathrm{SQH}, \mathrm{NQ}$, and LZ stations. Moreover, the ABL may be largely affected by the cumulative SHF in the daytime (Zhang et al., 2019). Thus we analyse the possible effect of SHF on the ABL. Figure 9a-c presents the scatter plots between the mean SHF over the past $6 \mathrm{~h}$ and the ABL height at $\mathrm{SQH}, \mathrm{NQ}$, and LZ stations. As shown in this figure, the correlation is $0.80,081$, and 0.71 (significant at the $99 \%$ confidence level) at these stations, respectively. When SHF is strong, the turbulent motion is strong, and the ABL develops, which is consistent with the result of Q. Zhang et al. (2011). Their result shows a significant correlation of 0.78 in the arid area of Northwest China between the ABL thickness and the cumulative SHF. Figure 10a and $b$ further present the features of the ABL height and SHF at SQH, NQ, and LZ stations. The mean value of SHF is 85,42 , and $33 \mathrm{Wm}^{-2}$ at $\mathrm{SQH}, \mathrm{NQ}$, and GZ stations, respectively, and has a large dif- ference $\left(52 \mathrm{~W} \mathrm{~m}^{-2}\right)$ between $\mathrm{SQH}$ and NQ stations. This result indicates a decreasing trend of SHF from west to east in the TP, consistent with a reduction in the ABL height from SQH via NQ to LZ station (shown in Figs. 3 and 10a). In addition, Fig. 11 demonstrates the diurnal variations in SHF and the $\mathrm{ABL}$ height at $\mathrm{SQH}, \mathrm{NQ}$, and $\mathrm{LZ}$ stations. The duration of positive SHF in a diurnal cycle at SQH, NQ, and GZ stations is 14,12 , and $11 \mathrm{~h}$, respectively, and indicates a decreasing trend from west to east in the TP. It is clear that the peak of the SHF occurs earlier than the maximum ABLH in a diurnal cycle at $\mathrm{SQH}$ station. The maximum ABL height occurs near 20:00 BJT (approximately 17:20 LST), corresponding to a strong SHF. At LZ station, however, the SHF turns into a negative value at 20:00 BJT (18:20 LST), and then the ABL height decreases. Some past studies show that the development of $\mathrm{ABL}$ height generally lags the development of SHF, and ABL depth growth continues even after SHF attains the maximum daytime value until the time of early evening 


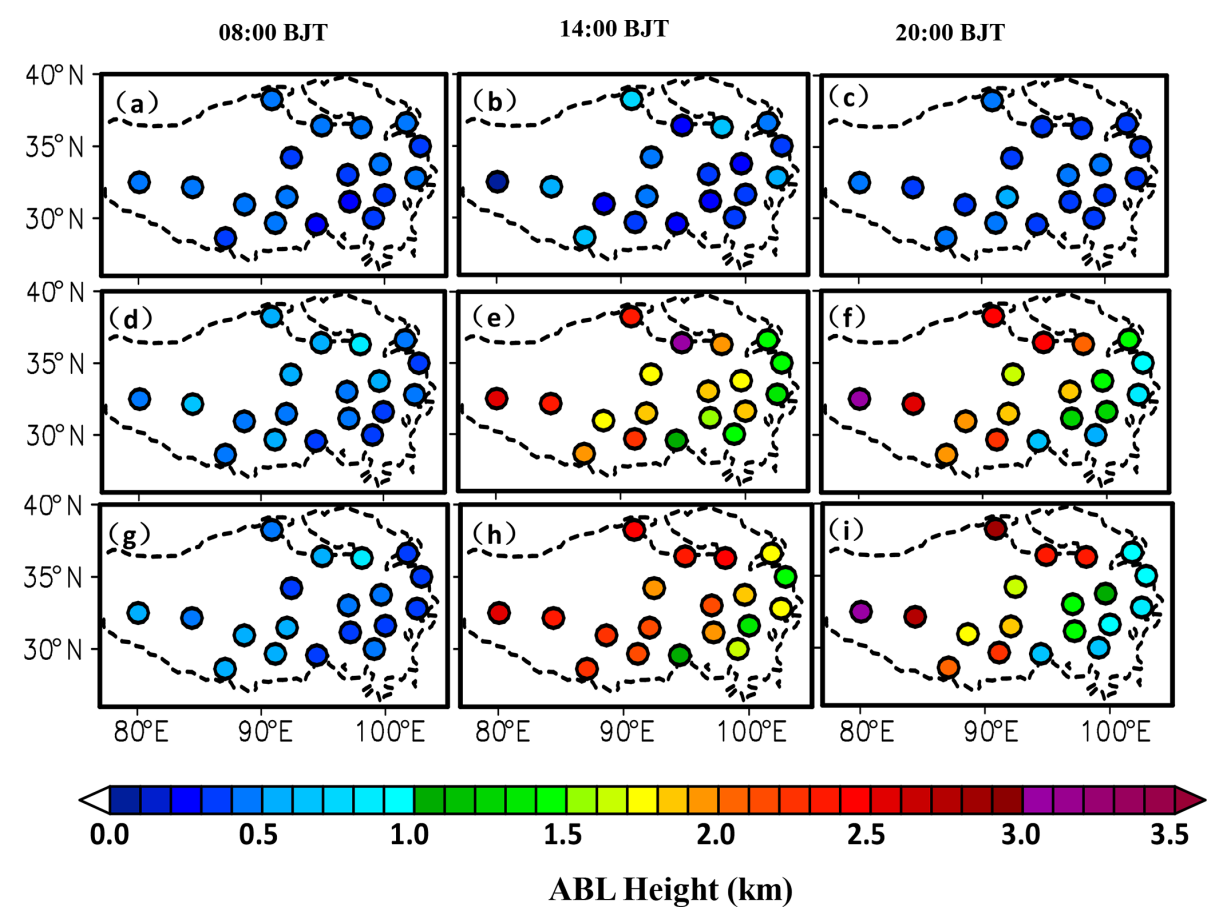

Figure 7. Spatial distributions of the mean ABLH for the SBL (a-c), NBL (d-f), and CBL (g-i) at 08:00, 14:00, and 20:00 BJT.

08:00 BJT

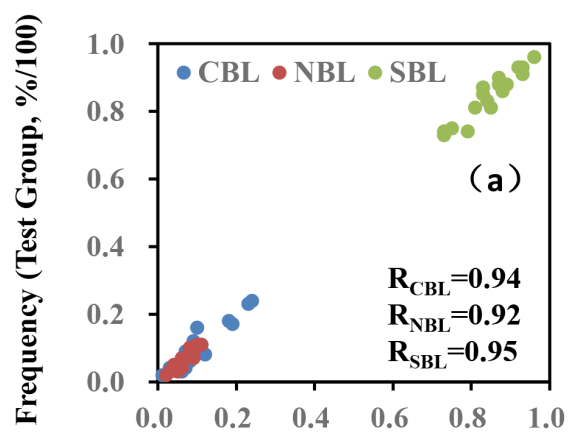

Frequency (Original Dataset, \%/100)

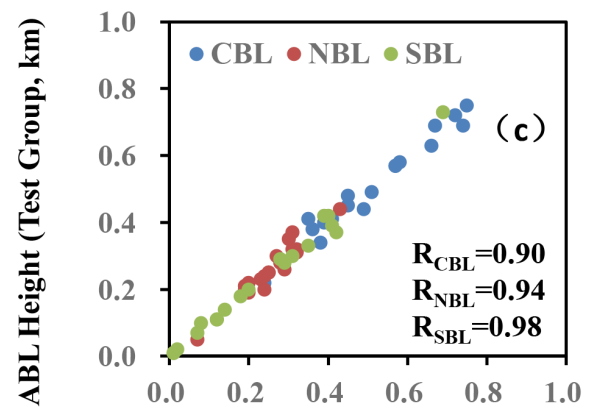

ABL Height (Original Dataset, $\mathrm{km})$
20:00 BJT

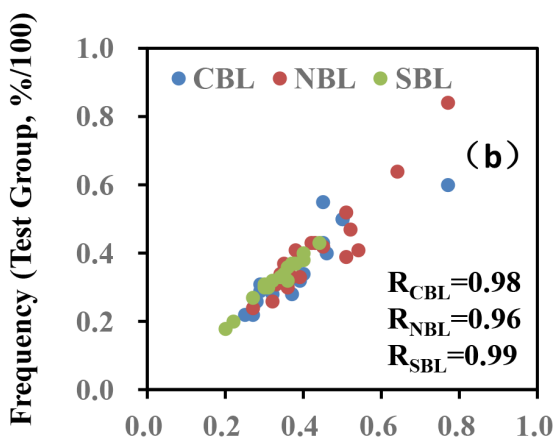

Frequency (Original Dataset, \%/100)

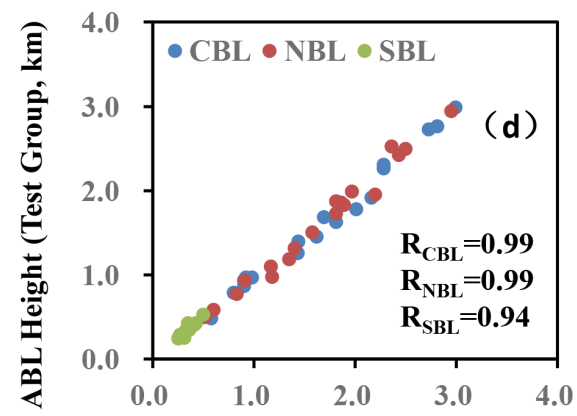

ABL Height (Original Dataset, km)

Figure 8. The scatter plots of occurrence frequency of the SBL, NBL, and CBL for the original and test group datasets at 19 stations at (a) 08:00 BJT and (b) 20:00 BJT; (c, d) same as in (a, b) but for the ABLH. 



Figure 9. Scatter plots of the ABLH and the $6 \mathrm{~h}$ average of surface sensible heat flux (SHF) (a-c), surface downward solar irradiance (DSR) (d-f), total cloud coverage (CLD) (g-i), and surface soil volume moisture content (VWC) (j-l) at 08:00, 14:00, and 20:00 BJT at $\mathrm{SQH}(\mathbf{a}, \mathbf{d}, \mathbf{g}, \mathbf{j})$, NQ (b, e, $\mathbf{h}, \mathbf{k})$, and LZ $(\mathbf{c}, \mathbf{f}, \mathbf{i}, \mathbf{l})$ stations in the study period. The correlation coefficient $(R)$ is given in each panel.
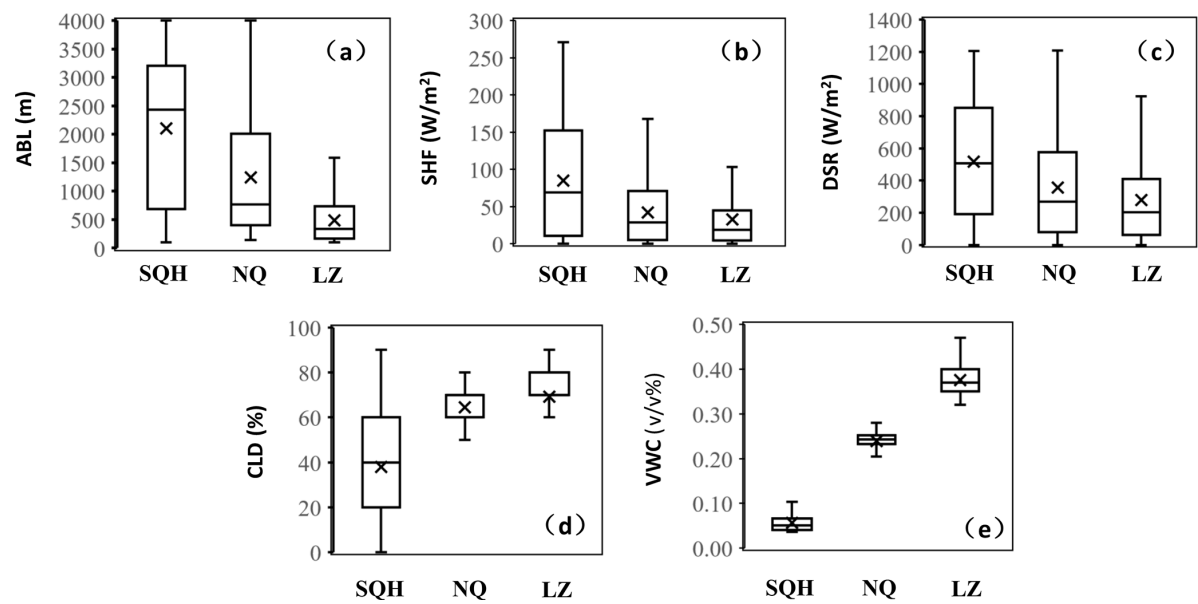

Figure 10. (a) The ABLH, (b) SHF, (c) DSR, (d) CLD, and (e) VWC at SQH, NQ, and LZ stations in the study period. Horizontal bars show the 5 th, 25th, 50th, 75th, and 95th percentile values, and " $\times$ " symbols show the corresponding mean value.

transitions (Chen et al., 2016; Zhang et al., 2019). Consequently, the difference in the ABL height between the WTP and ETP is closely associated with a west-east difference in SHF that is a direct thermal factor for the ABL development in the TP.

The solar radiation at the surface is an important component of the surface energy budget, affecting surface temper- ature and SHF. We show the scatter plots between the $6 \mathrm{~h}$ mean DSR and the ABL height at SQH, NQ, and LZ stations (Fig. 9d-f). The ABL height is highly correlated with the $6 \mathrm{~h}$ average of DSR at these stations, with correlation coefficients of $0.86,081$, and 0.73 , respectively, which is equivalent to those of SHF. The mean DSR shows a decreasing trend from $\mathrm{SQH}\left(510 \mathrm{~W} \mathrm{~m}^{-2}\right)$ to $\mathrm{LZ}\left(200 \mathrm{~W} \mathrm{~m}^{-2}\right)$ station. 



Time (h)

Figure 11. Diurnal variations in surface sensible heat flux (blue) and the ABLH (red) averaged over the study period at (a) SQH, (b) NQ, and (c) LZ stations.

Since the solar irradiance at the surface is negatively associated with the local cloud cover (Guo et al., 2016; Lin et al., 2016; Li et al., 2017; Zhang et al., 2017), the cloud cover is also correlated with the ABL height. Figure $9 \mathrm{~g}-\mathrm{i}$ shows that the $6 \mathrm{~h}$ mean CLD has significant correlations of -0.56 , -0.65 , and -0.54 with the ABL height at $\mathrm{SQH}, \mathrm{NQ}$, and $\mathrm{LZ}$ stations, respectively. A decrease in the mean ABL height from SQH to LZ station (Fig. 10a) corresponds to an increase in cloud cover (Fig. 10d) and a decrease in DSR (Fig. 10c). When cloud cover is between $0 \%$ and $20 \%$, the mean ABL height for the NBL and CBL is $2019 \mathrm{~m}$ a.g.l. (2732 $\mathrm{m}$ a.g.l.) in the ETP (WTP), and when cloud cover is $>80 \%$, the ABL height decreases to $741 \mathrm{~m}$ a.g.l. (1626 ma.g.l.) in the ETP (WTP) (Fig. 12). Therefore, the increased cloud cover inhibits the development of both the NBL and CBL. The difference in cloud cover between the WTP and ETP contributes to the west-east distribution of DSR and SHF, also finally contributing to the difference in the ABL development. Corresponding to more cloud cover in the ETP, the local ABL is more closely associated with atmospheric moisture processes.

Soil moisture is also an important factor affecting SHF. Low soil moisture generally coincides with a high surface sensible heat flux, which facilitates the ABL development (e.g. McCumber and Pielke, 1981; Sanchez-Mejia and Papuga, 2014; Rihani et al., 2015). Figure 9j-1 shows that the relationship between the ABL height and the $6 \mathrm{~h}$ mean VWC at SQH, NQ, and LZ stations. The ABL height at LZ station is negatively correlated with the local soil moisture, with a significant correlation coefficient of -0.45 . This result indicates that the ABL height is lower when surface soil is moister. However, the negative correlation is weaker at $\mathrm{SQH}$

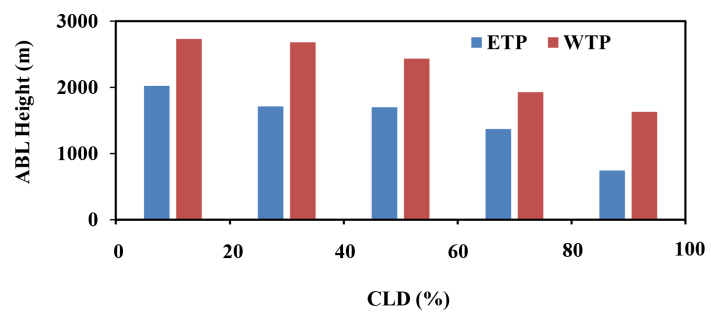

Figure 12. The mean ABLH (for the NBL and CBL) and CLD over the ETP (blue) and WTP (red) in the daytime (14:00 and 20:00 BJT).

station, with a correlation coefficient of -0.21 . This difference between the WTP and the ETP may be associated with the climatic feature of the local soil moisture. The surface type transitions from alpine meadow with few shrubs and trees or alpine steppe in the ETP to bare soil with few obstacles in the WTP (Wang et al., 2016). Accordingly, soil moisture decreases gradually from the ETP to the WTP (Fig. 10e), with a mean value of soil moisture below $0.10 \mathrm{~m}^{3} \mathrm{~m}^{-3}$ at $\mathrm{SQH}$ station and $0.38 \mathrm{~m}^{3} \mathrm{~m}^{-3}$ at LZ station. Little soil moisture in the WTP weakly modulates the local surface heat flux, which may lead to a weak correlation between the ABL height and soil moisture in the WTP.

\section{Summary and discussion}

Using the summer TIPEX-III intensive and meteorological operational observational datasets, we examine the ABL features and the relationships of the ABL height with surface sensible heat flux, solar radiation, cloud cover, and soil moisture in the TP region. The main conclusions are summarized as follows.

Generally speaking, the ABL height exhibits diurnal variations and regional differences in the TP, especially for the CBL and NBL. These features are weak for the SBL. Compared to the ETP, the ABL in the WTP has the larger amplitude of the diurnal variation and the longer development time. In the early morning (LST), the ABL height is generally low over the TP, not showing a large west-east difference, and the distribution of the ABL height is narrow, with $78.5 \%$ of the ABL height $<500 \mathrm{~m}$ a.g.l. At noon (LST), the CBL and NBL heights remarkably increase and have a wide distribution in the ABL height up to $4000 \mathrm{~m}$ a.g.l., with more than $50 \%$ of the ABL height exceeding $1900 \mathrm{~m}$ a.g.l. Their heights exhibit a large west-east difference. At this moment, the distribution of the SBL height is also narrow, with a cumulative frequency of $80 \%$ at a height of $500 \mathrm{ma.g} .1$., and there is no remarkable west-east difference. In the late afternoon (LST), there is a narrow distribution of the SBL height and wide distributions of both the NBL and CBL heights. At this moment, the ABL height continues to increase in the WTP, while it begins to decrease in the ETP. This feature re- 




Figure 13. The schematic diagram for relationships between the ABLH and the influential factors in the ETP and the WTP.

sults in a larger west-east difference in the ABL height. In spite of a cold environment in the TP (relative to plain areas), the WTP still has an ABL height above $2000 \mathrm{~m}$ a.g.l., which is similar to some extreme hot and arid areas such as Dunhuang and Taklimakan deserts. In the ETP, the ABLH is similar to that in North China (1500-1900 m a.g.l) and is generally larger compared to the East Asian summer monsoon region $(<1500 \mathrm{~m}$ a.g.l) such as the Yangtze River Delta and the Pearl River Delta (Zhang et al., 2011, 2017; Guo et al., 2016; Qiao et al., 2019).

The occurrence frequency of the SBL and CBL in the TP shows remarkable temporal variations. Most (few) of the SBLs (CBLs) occur in the early morning, and the occurrence frequency rapidly decreases (increases) at noon (LST), accounting for $3.6 \%(76.9 \%)$ of the ABL in the TP. Possibly owing to a difference in the solar elevation angle with respect to longitude in the late afternoon (LST), the SBL and CBL dominate the ETP and WTP, respectively. However, the NBL shows a relatively weak temporal variation over the TP, with a mean occurrence frequency of $6.4 \%$ in the early morning and around $20 \%$ at noon and in the late afternoon (LST).

The ABL height is significantly correlated with SHF, DSR, and cloud cover in the TP and is also closely associated with soil moisture in the ETP. The decreasing trends in both SHF and DSR and the increasing trends in both cloud cover and soil moisture from west to east may cause the corresponding west-east reduction in the ABL height. In the WTP (ETP), with low (high) cloud cover, there is larger (smaller) downward solar radiation at the surface. Meanwhile, corresponding to bare soil (alpine meadow or steppe) in the WTP (ETP), there is a dry (wet) soil condition. These features cause high (low) sensible heat flux, thus promoting (inhibiting) the local ABL development. The above factors affecting the WET and ETP ABL heights are summarized in Fig. 13.

The Tibetan Plateau is an area very sensitive to global climate change and exerts important thermal and dynamical effects on the general circulation and climate through the unique and complex land surface and boundary layer processes. Owing to new sounding observations in the WTP, our analysis reveals remarkable west-east differences in the ABL height, occurrence frequency, and diurnal amplitude over the TP region during summer for the first time. It is noted that there is a big drop in the CBL height, from 3000-4000 to 1000-2000 m a.g.l., from the WTP to the ETP. Such a steep west-east inhomogeneity in the TP (with an east-west spatial scale of about $2000 \mathrm{~km}$ ) is remarkably different from the regional variability in the ABLH on much larger scales ( $\sim 4000 \mathrm{~km}$ ), such as in the United States (Seidel et al., 2012) and in China (Guo et al., 2016). This unique inhomogeneity in the TP may trigger the local mesoscale circulation, convection, and precipitation according to relationships among surface heating, ABL, and convection activities (Segal and Arritt, 1992; Goutorbe et al., 1997; Huang et al., 2009; Zhang et al., 2019; Qiao et al., 2019). Therefore, the influences of the west-east differences in the ABLH over the TP on the local weather and climate should be further studied in the future. In addition, this study merely investigates the characteristics of the summer ABLH in the TP due to the limitation of the intensive-sounding observations. More efforts should be made to expand the climatology of ABLH to other seasons in the TP when more sounding data are available.

Code and data availability. The TIPEX-III original observations used in this study are available on its website (http://data.cma.cn/ tipex; last access: 10 March 2021). The calculation code and derived data in this study are open and available by contacting Junhui Che (chejunhui9@163.com).

Competing interests. The authors declare that they have no conflict of interest.

Author contributions. JC designed the study, analysed the data, and wrote the manuscript. PZ contributed to the study design, supervision, and writing of the manuscript.

Acknowledgements. We thank the TIPEX-III for providing the data available on its home pages (http://data.cma.cn/tipex, last access: 21 March 2021). This work is supported by the National Key Research and Development Program of China and the Strategic Priority Research Program of the Chinese Academy of Sciences.

Financial support. This research has been supported by the National Key Research and Development Program of China (grant no. 2018YFC1505700) and the Second Scientific Expedition to the Qinghai-Tibet Plateau (grant no. 2019QZKK020803).

Review statement. This paper was edited by Peter Haynes and reviewed by three anonymous referees. 


\section{References}

Blay-Carreras, E., Pino, D., Vilà-Guerau de Arellano, J., van de Boer, A., De Coster, O., Darbieu, C., Hartogensis, O., Lohou, F., Lothon, M., and Pietersen, H.: Role of the residual layer and large-scale subsidence on the development and evolution of the convective boundary layer, Atmos. Chem. Phys., 14, 4515-4530, https://doi.org/10.5194/acp-14-4515-2014, 2014.

Bosveld, F. C., Baas, P., Steeneveld, G., Holtslag, A. A. M., Angevine, W. M., Bazile, E., Bruijn, E. I. F., Deacu, D., Edwards, J. M., Ek, M., Larson, V. E., Pleim, J. E., Raschendorfer, M., and Svensson, G.: The third GABLS intercomparison case for evaluation studies of boundary-layer models, Part B: Results and process understanding, Bound.-Lay. Meteorol., 152, 157-187, https://doi.org/10.1007/s10546-014-9919-1, 2014.

Brooks, I. M. and Rogers, D. P.: Aircraft observations of the mean and turbulent structure of a shallow boundary layer over the Persian Gulf, Bound.-Lay. Meteorol., 95, 189-210, https://doi.org/10.1023/A:1002623712237, 2000.

Chen, S. S. and Houze, R. A.: Diurnal variation and lifecycle of deep convective systems over the tropical $\mathrm{Pa}$ cific warm pool, Q. J. Roy. Meteor. Soc., 123, 357-388, https://doi.org/10.1002/qj.49712353806, 1997.

Chen, X. L., Juan, A. Añel., Su, Z. B., Laura, de. La. Torre., Hennie, Kelder., Jacob, van. Peet., and Ma, Y. M.: The deep atmospheric boundary layer and its significance to the stratosphere and troposphere exchange over the Tibetan Plateau, PLoS. ONE, 8, e56909, https://doi.org/10.1371/journal.pone.0056909, 2013.

Chen, X. L., Škerlak, B., Rotach, M. W., Juan, A. Anel., Su, Z. B., Ma, Y. M., and Li, M. S.: Reasons for the extremely high-ranging planetary boundary layer over the Western Tibetan Plateau in winter, J. Atmos. Sci., 73, 2021-2038, https://doi.org/10.1175/jas-d-15-0148.1, 2016.

Dai, C., Wang, Q., Kalogiros, J. A., Lenschow, D. H., Gao,Z., and Zhou, M.: Determining boundary-layer height from aircraft measurements, Bound.-Lay. Meteorol., 152, 277-302, https://doi.org/10.1007/s10546-014-9929-z, 2014.

Davy, R.: The climatology of the atmospheric boundary layer in contemporary global climate models, J. Climate, 31, 9151-9173, https://doi.org/10.1175/JCLI-D-17-0498.1, 2018.

Davy, R. and Esau, I.: Differences in the efficacy of climate forcings explained by variations in atmospheric boundary layer depth, Nat. Commun., 7, 11690, https://doi.org/10.1038/ncomms11690, 2016.

Driedonks, A. G. M. and Tennekes, H.: Entrainment effects in the well-mixed atmospheric boundary layer, Bound.-Lay. Meteorol., 30, 75-105, https://doi.org/10.1007/BF00121950, 1984.

Esau, I. and Zilitinkevich, S.: On the role of the planetary boundary layer depth in the climate system, Adv. Sci. Res., 4, 63-69, https://doi.org/10.5194/asr-4-63-2010, 2010.

Garratt, J. R.: The Atmospheric Boundary Layer, Cambridge, Univ. Press., 37, 89-134, https://doi.org/10.1007/3-211-380787_4, 1992.

Garratt, J. R.: Sensitivity of climate simulations to land-surface and atmospheric boundary-layer treatments-A review, J. Climate, 6, 419-448, https://doi.org/10.1175/1520-0442(1993)006< 0419:socstl> 2.0.co;2, 1993.

Goutorbe, J. P., Lebel, T., Dolman, A. J., Gash, J. H. C., Kabat, P., Kerr, Y. H., Monteny, B., Prince, S. D., Stricker, J. N. M., Tinga, A., and Wallace, J. S.: An overview of HAPEX-Sahel: A study in climate and desertification, J. Hydrol., 188-189, 4-17, https://doi.org/10.1016/S0022-1694(96)03308-2, 1997.

Guo, J., Miao, Y., Zhang, Y., Liu, H., Li, Z., Zhang, W., He, J., Lou, M., Yan, Y., Bian, L., and Zhai, P.: The climatology of planetary boundary layer height in China derived from radiosonde and reanalysis data, Atmos. Chem. Phys., 16, 13309-13319, https://doi.org/10.5194/acp-16-13309-2016, 2016.

Guo, J. P., Zhang, X. Y., Che, H. Z., Gong, S. L., An, X., and Cao, C. X.: Correlation between PM concentrations and aerosol optical depth in eastern China, Atmos. Environ., 43, 5876-5886, https://doi.org/10.1016/j.atmosenv.2009.08.026, 2009.

Holtslag, B. and Boville, B. A.: Local versus nonlocal boundary-layer diffusion in a global climate model, J. Climate, 6, 1825-1842, https://doi.org/10.1175/15200442(1993)0062.0.CO;2,1993.

Hong, J., Guo, J., Du, J., and Wang, P.: An observational study on the vertical structure of the upper troposphere and lower stratosphere in Gaize, Tibet during the rainy season, Acta Meteorol. Sin., 74, 827-836, https://doi.org/10.11676/qxxb2016.05, 2016.

Huang, J. P., Minnis, P., Yi, Y., Tang, Q., Wang, X., Hu, Y., Liu, Z., Ayers, K., Trepte, C., and Winker, D.: Summer dust aerosols detected from CALIPSO over the Tibetan Plateau, Geophys. Res. Lett., 34, L18805, https://doi.org/10.1029/2007GL029938, 2007.

Huang, Q., Marsham, J. H., Parker, D. J., Tian, W., and Weckwerth, T.: A comparision of roll and nonroll convection and the subsequent deepening moist convection: An LEM case study based on SCMS data, Mon. Weather Rev., 137, 350-365, https://doi.org/10.1175/2008MWR2450.1, 2009.

Lee, T. R. and Pal, S.: On the potential of 25 Years (19912015) of rawinsonde measurements for elucidating climatological and spatiotemporal patterns of afternoon boundary layer depths over the contiguous US, Adv. Meteorol., 2017, 6841239, https://doi.org/10.1155/2017/6841239, 2017.

Lee, T. R. and Pal, S.: The impact of height-independent errors in state variables on the determination of the daytime atmospheric boundary layer depth using the bulk Richardson approach, J. Atmos. Ocean. Tech., 38, 47-61, https://doi.org/10.1175/JTECHD-20-0135.1, 2021.

Li, J. L., Hong, Z. X., and Sun, S. F.: An observational experiment on the atmospheric boundary layer in Gerze area of the Tibetan Plateau, Chinese J. Atmos. Sci., 24, 301-312, https://doi.org/10.3878/j.issn.1006-9895.2000.03.02, 2000.

Li, M. S., Ma, Y. M., Ma, W. Q., I, Hirohiko., Sun, F. L., and Ogino, S. Y.: Structural difference of atmospheric boundary layer between dry and rainy seasons over the central Tibetan Plateau, J. Glaciol. Geocryol., 33, 72-79, https://doi.org/10.3969/j.issn.1000-6826.2014.06.03, 2011.

Li, N., Zhao, P., Wang, J., and Deng, Y.: Estimation of surface heat fluxes over the central Tibetan Plateau using the maximum entropy production model, J. Geophys. Res.-Atmos., 124, 68276840, https://doi.org/10.1029/2018JD029959, 2019.

Li, N., Zhao, P., Wang, J., and Deng, Y.: The Long-Term Change of Latent Heat Flux over the Western Tibetan Plateau, AtmosphereBasel, 11, 262, https://doi.org/10.3390/atmos11030262, 2020.

Li, Y. and Gao, W.: Atmospheric boundary layer circulation on the eastern edge of the Tibetan Plateau, China, in summer, Arct. Antarct. Alp. Res., 39, 708-713, https://doi.org/10.1657/15230430(07-50 4)[1i]2.0.co;2, 2007. 
Li, Z., Guo, J., Ding, A., Liao, H., Liu, J., and Sun, Y.: Aerosol and boundary-layer interactions and impact on air quality, Natl. Sci. Rev., 4, 810-833, https://doi.org/10.1093/nsr/nwx117, 2017.

Lin, Y., Wang, Y., Zhang, R., and Liu, Y.: Response of boundary layer clouds to continental pollution during the RACORO campaign, J. Atmos. Sci., 73, 3681-3700, https://doi.org/10.1175/JAS-D-15-0361.1, 2016.

Liu, H. Y. and Miao, M. Q.: Preliminary analysis on characteristics of boundary layer in Qinghai-Tibet Plateau, Journal of Nanjing University (Natural Sciences), 37, 348-357, https://doi.org/10.3321/j.issn:0469-5097.2001.03.013, 2001.

Liu, S. H., Xu, Y., and $\mathrm{Hu}, \mathrm{F}$. U Using a Modified Soil-PlantAtmosphere Scheme (MSPAS) to simulate the interaction between land surface processes and atmospheric boundary layer in semi-arid regions, Adv. Atmos. Sci., 21, 245-259, https://doi.org/10.1007/bf02915711, 2004.

Liu, S. Y. and Liang, X. Z.: Observed diurnal cycle climatology of planetary boundary layer height, J. Climate, 23, 5790-5809, https://doi.org/10.1175/2010JCLI3552.1, 2010.

Lü, Y. Q., Ma, Y. M., Li, M. S., and Sun, F. L.: Study on characteristic of atmospheric boundary layer over Lake Namco region, Tibetan Plateau, Plateau Meteor., 27, 1205-1210, 2008.

McCumber, M. C. and Pielke, R. A.: Simulation of the effects of surface fluxes of heat and moisture in a mesoscale numerical model: 1. Soil layer, J. Geophys. Res., 86, 9929-9938, https://doi.org/10.1029/JC086iC10p09929, 1981.

Medeiros, B., Hall, A., and Stevens, B.: What controls the mean depth of the PBL?, J. Climate, 18, 3157-3172, https://doi.org/10.1175/JCLI3417.1, 2005.

Miao, Y. C., Hu, X. M., Liu, S. H., Qian, T. T., Xue, M., Zheng, Y. J., and Wang, S.: Seasonal variation of local atmospheric circulations and boundary layer structure in the Beijing-Tianjin-Hebei region and implications for air quality, J. Adv. Model. Earth Sy., 7, 1602-1626, https://doi.org/10.1002/2015MS000522, 2015.

Pal, S. and Haeffelin, M.: Forcing mechanisms governing diurnal, seasonal, and interannual variability in the boundary layer depths: Five years of continuous lidar observations over a suburban site near Paris, J. Geophys. Res.-Atmos., 120, 11936-11956, https://doi.org/10.1002/2015JD023268, 2015.

Poulos, G. S., Blumen, W., Fritts, D. C., Lundquist, J. K., Sun, J., Burns, S. P., Nappo, C., Banta, R., Newsom, R., Cuxart, J., Terradellas, E., Balsley, B., and Jensen, M.: CASES-99: A comprehensive investigation of the stable nocturnal boundary layer, Bull. Amer. Meteor. Soc., 83, 555-581, https://doi.org/10.1175/15200477(2002)083<0555:CACIOT>2.3.CO;2, 2002.

Qiao, L., Zhang, Q., Yue, P. and Jin, H. M.: Analysis of changes in the structure of atmospheric boundary layer from non-monsoon zone to monsoon zone, Chinese J. Atmos. Sci., 43, 251-265, https://doi.org/10.3878/j.issn.1006-9895.1805.17231, 2019.

Raman, S., Templeman, B., Templeman, S., Holt, T., Murthy, A. B., Singh, M. P., Agarwaal, P., Nigam, S., Prabhu, A., and Ameenullah, S.: Structure of the Indian southwesterly pre-monsoon and monsoon boundary layers: Observations and numerical simulation, Atmos. Environ., 24, 723-734, https://doi.org/10.1016/0960-1686(90)90273-p, 1990.

Rihani, J. F., Chow, F. K., and Maxwell, R. M.: Isolating effects of terrain and soil moisture heterogeneity on the atmospheric boundary layer: Idealized simulations to diagnose land atmosphere feedbacks, J. Adv. Model. Earth Sy., 7, 915-937, https://doi.org/10.1002/2014MS000371, 2015.

Sanchez-Mejia, Z. M. and Papug, S. A.: Observations of a two-layer soil moisture influence on surface energy dynamics and planetary boundary layer characteristics in a semiarid shrubland, Water Resour. Res., 50, 306-317, https://doi.org/10.1002/2013WR014135, 2014.

Segal, M. and Arritt, R. W.: Nonclassical mesoscale circulations caused by surface sensible heat-flux gradients, Bull. Amer. Meteor. Soc., 73, 1593-1604, https://doi.org/10.1175/15200477(1992)0732.0.CO;2, 1992.

Seibert, P., Beyrich, F., Gryning, S. E., Joffre, S., Rasmussen, A., and Tercier, P.: Review and intercomparison of operational methods for the determination of the mixing height, Atmos. Environ., 34, 1001-1027, https://doi.org/10.1016/s1352-2310(99)00349$0,2000$.

Seidel, D. J., Ao, C. O., and Li, K.: Estimating climatological planetary boundary layer heights from radiosonde observations: Comparison of methods and uncertainty analysis, J. Geophys. Res.-Atmos., 115, D16113, https://doi.org/10.1016/s13522310(99)00349-0, 2010.

Seidel, D. J., Zhang, Y., Beljaars, A., Golaz, J.-C., Jacobson, A. R., and Medeiros, B.: Climatology of the planetary boundary layer over the continental United States and Europe, J. Geophys. Res.Atmos., 117, D17106, https://doi.org/10.1029/2012jd018143, 2012.

Song, Z. S., Zhu, B., Sun, G. W.: A preliminary study on the thermal mixing layer in the western Tibetan Plateau, the Collected Works of the Tibetan Plateau Meteorological Scientific Experiment (Series 2), Beijing: Science Press, 253-261, 1984

Stull, R. B.: An Introduction to Boundary Layer Meteorology, Springer Netherlands, https://doi.org/10.1007/978-94-009-30278, 1988.

Sun, F., Ma, Y., and Li, M.: Boundary layer effects above a Himalayan valley near Mount Everest, Geophys. Res. Lett., 34, L08808, https://doi.org/10.1029/2007g1029484, 2007.

Tao, S. Y. and Ding, Y. H.: Observational evidence of the influence of the Qinghai-Xizang (Tibet) Plateau on the occurrence of heavy rain and severe convective storms in China, Bull. Amer. Meteor. Soc., 62, 23-30, https://doi.org/10.1175/15200477(1981)062h0023:OEOTIOi2.0.CO;2, 1981.

Wang, Y. J., Xu, X. D., Liu, H. Z., Li, Y. Q., Li, Y. H., Hu, Z. Y., Gao, X. Q., Ma, Y. M., and Sun, J. H., Lenschow, D. H., Zhong, S. Y., Zhou, M. Y., Bian, X. D., Zhao, P., Wang, Y. J.: Analysis of land surface parameters and turbulence characteristics over the Tibetan Plateau and surrounding region, J. Geophys. Res.-Atmos., 121, 9540-9560, https://doi.org/10.1002/2016JD025401, 2016.

Xu, X. D., Zhou, M. Y., Chen, J. Y., Bian, L. G., Zhang, G. Z., Liu, H. Z., Li, S. M., Zhang, H. S., Zhao, Y. J., Suolong, D., and Wang, J. Z.: A comprehensive physical pattern of land-air dynamic and thermal structure on the Qinghai-Xizang Plateau, Sci. China Ser. D, 45, 577-594, https://doi.org/10.1360/0 2yd9060, 2002.

Yanai, M. and Li, C.: Mechanism of heating and the boundary layer over the Tibetan Plateau, Mon. Weather Rev., 122, 305-323, https://doi.org/10.1175/1520-0493(1994)1222.0.CO;2, 1994.

Yang, K., Koike, T., Fujii, H., Tamura, T., Xu, X., Bian, L., and Zhou, M. Y.: The daytime evolution of the atmospheric boundary layer and convection over the Tibetan Plateau: ob- 
servations and simulations, J. Meteor. Soc., 82, 1777-1792, https://doi.org/10.2151/jmsj.82.1777, 2004.

Ye, D., Gao, Y. X.: The Meteorology of the Qinghai-Xizang Plateau, Beijing: Science Press, 89-101, 1979.

Yu, X. J., Du, J., Wang, M. Z., Xu, H. X., and He, Q.: Impact of assimilating the new radiosonde data on Qinghai-Tibetan Plateau on summer rainfall forecast over southern Xinjiang, Plateau Meteor., 37, 13-27, https://doi.org/10.7522/j.issn.10000534.2017.00034, 2018.

Zhang, G., Xu, X., and Wang, J.: A dynamic study of Ekman characteristics by using 1998 SCSMEX and TIPEX boundary layer data, Adv. Atmos. Sci., 20, 349-356, https://doi.org/10.1007/bf02690793, 2003.

Zhang, Q., Zhang, J., Qiao, J., and Wang, S.: Relationship of atmospheric boundary layer depth with thermodynamic processes at the land surface in arid regions of China, Sci. China Earth Sci., 54, 1586-1594, https://doi.org/10.1007/s11430-011-42070, 2011.

Zhang, Q., Yue, P., Zhang, L., Wang, S., Zhang, J., Zhao, J. H., Wang, R. Y., and Yang, F. L.: Land-atmosphere interaction over the summer monsoon transition zone in China: A review and prospects, Acta Meteorol. Sin., 77, 758-773, https://doi.org/10.11676/qxxb2019.038, 2019.

Zhang, W., Guo, J., Miao, Y., Liu, H., Yang, S., Fang, Z., He, J., Lou, M. Y., Yan, Y., Li, Y., and Zhai, P. M.: On the summertime planetary boundary layer with different thermodynamic stability in China: a radiosonde perspective, J. Climate, 31, 1451-1465, https://doi.org/10.1175/jcli-d-17-0231.1, 2017.

Zhang, Y., Seidel, D. J., Golaz, J.-C., Deser, C., and Tomas, R. A.: Climatological characteristics of Arctic and Antarctic surface-based inversions, J. Climate., 24, 5167-5186, https://doi.org/10.1175/2011JCLI4004.1, 2011.

Zhao, C. L., Li, Y. H., Liu, Y. P., Zhou, G. L., and Sun, X. Y.: The variation characteristics of planetary boundary layer height in Northwest China: Based on radiosonde and ERA-Interim reanalysis data, Plateau Meteor., 38, 1181-1193, https://doi.org/10.7522/j.issn.1000-0534.2018.00152, 2019.
Zhao, J. H., Zhang, Q., and Wang, S.: A simulative study of the thermal mechanism for development of the convective boundary layer in the arid zone of Northwest China, Acta Meteorol. Sin., 69, 1029-1037, https://doi.org/10.11676/qxxb2011.090, 2011.

Zhao, M., Miao, M. Q.: The atmospheric boundary layer, Beijing: China Meteorological Press, 1992.

Zhao, P., Xu, X., Chen, F., Guo, X., Zheng, X., Liu, L., Hong, Y., Li, Y., La, Z., Peng, H., Zhong, L., Ma, Y., Tang, S., Liu, Y., Liu, H., Li, Y., Zhang, Q., Hu, Z., Sun, J., Zhang, S., Dong, L., Zhang, H., Zhao, Y., Yan, X., Xiao, A., Wan, W., Liu, Y., Chen, J., Liu, G., Zhaxi, Y., and Zhou, X.: The Third Atmospheric Scientific Experiment for understanding the earth-atmosphere coupled system over the Tibetan Plateau and its effects, Bull. Amer. Meteor. Soc., 99, 757-776, https://doi.org/10.1175/BAMS-D-16-0050.1, 2018.

Zhao, P., Zhou, X., Chen, J., Liu, G., and Nan, S.: Global climate effects of summer Tibetan Plateau, Sci. Bull., 64, 1-3, https://doi.org/10.1016/j.scib.2018.11.019, 2019a.

Zhao, P., Li, Y. Q., Guo, X., Xu, X., Liu, Y., Tang, S., Xiao, W., Shi, C., Ma, Y., Yu, X., Liu, H., Jia, L., Chen, Y., Liu, Y., Li, J., Luo, D., Cao, Y., Zheng, X., Chen, J., Xiao, A., Yuan, F., Chen, D., Pang, Y., Hu, Z., Zhang, S., Dong, L., Hu, J., Han, S., and Zhou, X.: The Tibetan Plateau surface -atmosphere coupling system and its weather and climate effects: The Third Tibetan Plateau Atmospheric Science Experiment, J. Meteor. Res., 33, 1-25, https://doi.org/10.1007/s13351-019-8602-3, 2019b.

Zhou, W., Yang, S. P., Jiang, X., and Guo, Q. Y.: Estimating planetary boundary layer height over the Tibetan Plateau using COSMIC radio occultation data, Acta Meteorol. Sin., 76, 117-133, https://doi.org/10.11676/qxxb2017.069, 2018.

Zuo, H. C., Hu, Y. Q., Lü, S. H., and Ma, Y. M.: Seasonal transition and its boundary layer characteristics in Anduo area of Tibetan Plateau, Prog. Nat. Sci., 14, 535-540, https://doi.org/10.3321/j.issn:1002-008X.2004.05.009, 2004. 